\title{
Dissent on Core Beliefs: Religious and Secular Perspectives. edited by Simone Chambers and Peter Nosco. New York: Cambridge University Press, 2015. 254p. \$99.00-CORRIGENDUM
}

Olivia Newman

doi: 10.1017/S1537592716003443. Published online by Cambridge University Press, 28 December 2016.

In the original published review by Newman, Peter Nosco's surname was misspelled. The surname has since been corrected in the title of the original review.

\section{Reference}

Newman, Olivia. "Dissent on Core Beliefs: Religious and Secular Perspectives. edited by Simone Chambers and Peter Nosco. New York: Cambridge University Press, 2015. 254p. \$99.00." Perspectives on Politics 14(4): 1188-1189. doi: 10.1017/S1537592716003443. 